\title{
Congenital ptosis
}

INSERM

\section{Source}

INSERM. (1999). Orphanet: an online rare disease and orphan drug data base. Congenital ptosis. ORPHA:91411

Congenital ptosis is characterized by superior eyelid drop present at birth. 